\title{
HEGEL. FILOSOFÍA DE LA HISTORIA Y FILOSOFÍA DE LA HISTORIA DE LA FILOSOFÍA*
}

RAMÓN XIRAU

INSTITUTO DE INVESTIGACIONES FiLOSÓFICAS Universidad Nacional autónoma de Mexico

Estas páginas remiten, principalmente a un libro de Hegel poco comentado entre nosotros: Lecciones sobre la historia de la filosofía. ${ }^{1}$ Sabemos que para Hegel el punto álgido es Espíritu Absoluto, tanto en la Lógica como en la Fenomenología del espiritu o la Filosofía de la historia. Sabemos también que, por decirlo con Kostas Papaioannou, para Hegel "los verdaderos protagonistas de la historia no son los grandes hombres, ni las masas que en aquellos reconocen 'su propio espíritu intérior saliéndoles al encuentro'; ni la humanidad, concepto abstracto que no designa más que una especie biológica entre otras. El espíritu no es un universal abstracto, sino que se encarna en pueblos particulares que expresan, cada uno a su manera y de acuerdo siempre con la etapa del desarrollo histórico, la humanidad y la universalidad". ${ }^{2}$

Naturalmente, o mejor dicho, "naturalmente" para Hegel, si la más alta forma del espíritu es la Idea, si ésta se muestra en el espíritu del filósofo, habrá de ofrecerse no sólo en la filosofía de la historia, vista como un creciente progreso del espíritu, sino, puesto que de la Idea se trata, en el desarrollo de la filosofía. De ahí que un momento culminante de la filosofía de Hegel sea la historia de la filosofía vista a la luz de lla filosofía, es decir, como parte álgida

- He trabajado a Hegel a lo larg( de los años y, recientemente, én seminarios en mi casa. El presente texto conistituye una faceta de estos trabajos.

1 La edición alemana corregida de estas Lecciones es de. 1842. La edición española está preparada por Elsa Ciecila Frost; traducida por Wenceslao Roces, México, Fondo de Cultura Económica, 1955.

2 En efecto, para Hegel, lo más concreto es lo más espiritual. Esta espiritualidad se muestra, sucesivamente, en los tres grandes "momentos" del Espíritu Absoluto (Estética, Religión, Filosoffa) y se entrega como una realización cada vez más perfecta de Dios o, mejor, e n el lenguaje hegeliano, de la Idea. El libro de Papaioannou, excelente y breve, e's Hegel, Madrid, EDAF, colección Filósofos de todos los tiempos, 1975. 
del espíritu humano y de su objeto, la Idea. ${ }^{3}$ Por lo demás, y a la manera de la filosofía de la historia, la filosofía de la historia de la filosofía es, toda ella, un movimiento de la conciencia humana, sin que tenga que pasar siempre, cosa que no sucede en el "mal lado de la historia", por la enajenación, desgarramiento que, una vez superado, es también parte de una suerte de "salvación" histórica. Hechas estas observaciones previas, paso a precisar lo que Hegel entiende por filosofía de la historia de la filosofía.

\section{I}

El 28 de octubre de 1816, en el Discurso inaugural pronunciado en la Universidad de Heidelberg como primera introducción a las Lecciones sobre la historia de la filosofía, Hegel dice que, después de pasar por una "mala época", se ha vuelto a desarrollar en Alemania, no en toda Europa, el amor por la libertad y la razón que caracterizan a la filosofía. Escribe Hegel: "El Espíritu del Mundo (Weltgeist), ocupado en demasía con esta realidad (la del mundo), no podía replegarse hacia dentro y concentrarse en sí mismo". Pero el Espíritu del Mundo es necesario si mediante él se renuevan las ciencias y hace que se desarrollen en un mundo racional, mundo libre (en Hegel racionalidad entraña siempre libertad), en pocas palabras el Mundo del Espíritu. A los alemanes, peculiaridad típica de Alemania, les toca "la alta misión de ser los guardianes de este fuego sagrado". En Atenas se asignaba al "linaje de las Eumópilas" ser "custodio de los misterios eleusinos..." Hegel, acaso esencialmente romántico a pesar de su querer ser racionalista, emplea, en este Discurso como en otras partes de su filosofía, un lenguaje emocional y metafórico, lenguaje que él negaba como vehículo de su filosofía. ${ }^{4}$ El Hegel de la madurez recuerda, sin duda, y más de lo que se ha pensado, al joven Hegel, el que con Schelling y Hölderlin quiso establecer una religión nueva y amorosa, y acaso también "hermética". Pero sigamos leyendo el Discurso de Hegel. Según sus expresiones, aquí muy frecuentemente metafóricas, en Alemania se

3 Tal vez donde mejor se resuma la filosoffa de Hegel sea en la Enciclopedia de las ciencies filosóficas (la traducción española es mediocre). En ella queda claro que el Dios de $\mathrm{Hegel,} \mathrm{Dios} \mathrm{ya} \mathrm{no} \mathrm{objetio} \mathrm{de} \mathrm{la} \mathrm{religión} \mathrm{revelada} \mathrm{sino} \mathrm{de} \mathrm{un}$ intelecto espiritualizado, es la Idea que Hegel ve como "vida perfecta y eterna", "duración continua y eterna". Así, en la Enciclopedia de las ciencias filosóficas culmina con una idea de Dios que se cifra en la "definición" aristotélica de la divinidad: Pensamiento que se piensa as símismo, si bien en Aristóteles la divinidad fuera limitada y en Hegel, infinita.

1 Puede leerse, para esta cuestion, mi libro Entre idolos y dioses. Thes ensayos sobre Hegel, México, El Colegio Nacional, 1980. 
encuentra el "foco de la razón"; el país "se encamina, hora tras hora, hacia su destino", el estado prusiano, "basado en la inteligencia", afirma la "fe en el espíritu". Así, la "esencia del universo" no podrá ya resistir a la verdad y tendrá que mostrarse en el "valor de un espíritu". Para hacerlo es necesario reflexionar acerca de la historia de la filosofía que, al ser estudiada desde "el punto de vista que se merece, será vista por dentro". En efecto, si el filósofo elige racionalmente los "acontecimientos que se narran", verá íntimamente esta historia, según el "concepto verdadero", el verdadero Begriff. ${ }^{5}$ $Y$, con el espíritu científico-metafísico, un espíritu que Hegel desea únicamente científico, afirma el filósofo que "si el conjunto de la filosofía ha de ser científico, llegaremos necesariamente a la conclusión de què este modo de enfocar el problema no es otro que la filosofia misma". ${ }^{6}$

No deja de ser extraña la noción misma de Espíritu del Mundo (Weltgeist), común a muchos románticos alemanes. Algunos, entre otros Châtelet, han interpretado esta noción como la de una manifestación de la Idea en el mundo; otros, así Franz Grégoire, como la presencia de "una ley racional en el mundo", cosa a mi modo de ver, más exacta. Más precisamente, y también siguiendo a Franz Grégoire, habría que añadir que el Espíritu del Mundo empieza por ser inconsciente y se va haciendo consciente en el curso de la historia y, naturalmente, de manera privilegiada, en el curso de la historia de la filosofía. ${ }^{7}$

Volvamos ahora al Discurso. La historia de la filosofía debe concebirse como "la galería de los héroes de la razón pensante". Esta "galería" culmina en la filosofía del propio Hegel.

\section{II}

Hasta aquí el Discurso; veamos ahora, paso a paso, algunos puntos clave de la Introducción a las Lecciones sobre la historia de la filosofía; veremos cómo conducen a una idea de la filosofía que no puede sino ser la hegeliana.

Por lo pronto, leemos, en un texto que se inicia algo vagamente, que la filosofía tiene en "su naturaleza interior" su propio destino. Este progresar hacia su destino propio es calificado por Hegel como "peculiar". Pronto se aclara su pensamiento. La idea de Hegel es,

5 Para la noción de Begriff, central en la filosofía de Hegel, véase un libro excepcional: Franz Grégoire, Études hegeliennes. Les points capitaux du système, Publications Universitaires de Louvain, 1958.

6 Cfr. ibid.

7 Cfr. Franz Grégoire, op. cit. 
en este punto, la de ver racionalmente el mundo del pensamiento para penetrar, por medio de la razón, en "la esencia de las cosas", la "naturaleza", en el "espíritu" y en la "esencia" de Dios mismo. Así, la evolución de la filosofía es la evolución misma del Espíritu (Geist) o, más exactamente, de un Espíritu Absoluto que se pretende racional, y se quiere racional. Pero aquí desaparece la "galería de los héroes", desaparece para que el pensamiento del pasado - las filosofías antigua, medieval, clásica - no sean imputables al "individuo", para que el pensamiento que en. Hegel lo es de todos los pensadores - todos y ninguno en particular- revele algo más aito que las individualidades: la "libertad" que en Hegel es "el pensamiento mismo". Nunca fue Hegel individualista y menos personalista. Leamos lo que sobre el asunto nos dice Kostas Papaioannou: "Detrás de las oposiciones teóricas, prácticas y religiosas entre sujeto y objeto, el hombre y la naturaleza, Dios y el mundo, detrás de la 'desdicha' que de esto resulta, se encuentra la experiencia inquieta de la historia, en la que se problematiza el destino mismo de la colectividad, porque únicamente la colectividad es el verdadero hombre concreto. El individuo es una 'abstracción' hipostasiada por el entendimiento. La realidad humana es supraindividual y total, y en esta totalidad, obra de todos y de cada uno, no se pueden aislar los diversos planos de existencia ni considerarlos como independientes. En una palabra, 'el espíritu de un pueblo, la historia, la religión, el grado de libertad política de un pueblo no pueden considerarse aisladamente: están unidos de manera indisoluble" ${ }^{8} 8$

En el pensamiento de Hegel siempre la comunidad es superior al individuo. Así, cuando nos habla del "espíritu objetivo" - familia, sociedad civil, Estado - trata de mostrar que el Estado no es tan sólo superior en espiritualidad a la sociedad civil o a la familia, sino al individuo mismo. Por esto puede escribir que el Estado es "divino". 9

Por una parte somos resultado de la historia; por otra, y complementariamente, somos "herederos"; "la razón consciente de sí misma es sustancialmente, no accidentalmente, "herencia". Hasta tal punto que lo histórico, si es racional, se convierte en el curso de la historia de la filosofía en series de "verdades" que van más allá de tiempo y lugar, que son transhistóricas.

8 Cfr. Kostas Papaioannou, op. cit.

- Este calificativo, sin duda excesivo, se acerca tal vez más a la doctrina de un despotismo ilustrado que a lo que hoy llamamos "totalitarismo". En efecto, para Hegel el Estado no es el Absoluto. Constituyen al verdadero Espíritu Absoluto, en una serie ascendente, la Belleza (objeto de la Estética), Dios (objeto de la religión revelada) y, finalmente, el Begriff absoluto, el Dios racionalizado de la Idea. 
La tradición filosófica "no es una estatua inmóvil, sino una corriente viva, cuyo caudal va creciendo a medida que se aleja de su punto de origen". ¿Qué se nos revela en esta tradición? Hay que repetirlo con Hegel; lo que se nos revela es el espíritu mismo bajo la forma de Espíritu del Mundo, nuevamente, renovadamente, el Weltgeist, espíritu racional si bien de difícil entendimiento. Hegel suele aproximarse a ver este Espíritu mediante imágenes. Así, entre otras, la que reza: "El espíritu universal no se está quieto".

Tenemos una herencia, la de la historia de la filosofía. Precisemos, ahora, el sentido de este espíritu universal, móvil y dinámico que, progresivamente, se va mostrando a través de la historia de la filosofía si bien mucha de la verdad de ésta estuviera ya en Grecia $y$, especialmente, en el pensamiento de Heráclito.

La hipótesis de herencia es todavía insuficiente si queremos precisar el sentido de la filosofía de la historia de la filosofía. Para que esta tradición esté viva es necesario "trabajarla" y verla como "el alma de cada generación". Si la historia nos muestra nuestro devenir de menor a mayor espiritualidad, la historia de la filosofía muestra; eminentemente, el desarrollo de la espiritualidad en la razón humana, su devenir conceptual y especulativo. Escribir la historia de la filosofía constituye una "introducción a la filosofía misma".

Aquí parecen necesarias dos observaciones:

1. Hegel lleva a cabo una suerte de "hermenéutica", una interpretación del curso y decurso del pensamiento racional. Hegel, lo veremos en algún caso, "hegelianiza", por así decirlo, a varios filósofos. Pero, ¿es posible la "interpretación"? Probablemente lo sea si la entendemos como una especie de traducción de un lenguaje a otro, de uno a otro pensamiento. La hermenéutica, lo sabemos, empezó como una interprebación de los Libros Sagrados. En nuestro siglo, principalmente Heidegger, pero también en buena medida Gadamer - Paul Ricœur, han visto la hermenéutica como una interpretación del mundo y, sobre todo el primero, como una ontología; en el caso de Gadamer, como una explicación de la historia del pensamiento que tiene en cuenta que el pasado se nos renueva al interpretarlo. ${ }^{10}$

2. Hegel descubre en la historia de la filosofía los conceptos de su propia lógica-ontológica y los pensamientos que desarrollará su propio espíritu; así, hay que ver la racionalidad desarrollada como un camino que adquiere plena realidad en el idealismo alemán del siglo XIX.

10 Excelente libro sobre el tema: E. Palmer, Hermeneutics: Interpretation Theory in Sehleiermacher, Dillhey, Heidegger and Gadamer, 1969. Imprescindible y original, Paul Riccur, Le conflit des interprétations: Essais d'herméneutique, 1969. 
Hechas estas dos observaciones, prosigamos con la teoría hegeliana de la filosofía de la historia de la filosofía.

Las filosofías son siempre (o deben ser) manifestaciones del pensamiento o no son nada. En ellas "el pensamiento se encuentra a sí mismo" y, por lo,tanto, en este encontrarse, está la razón reflexiva, es decir, la filosofía misma.

Pero, y Hegel se da claramente cuenta del problema, si cada filosofía auténtica es la filosofáa, "¿cómo explicarse que este mundo intelectual tenga una historia?". La pregunta es seria porque la historia es devenir y cambio; la filosofía, por su parte, cuando es "verdadera" y necesaria "no es susceptible de cambio". Trabajo crucial para quien haga historia de la filosofía será la de determinar lá filosofía que subraya a todas las filosofías particulares, siempre que éstas sean "verdaderas" - cuestión de criterio que Hegel no acába de aclarar nunca. Lo más probable es que lo que Hegel se propone sea más que difícil, acaso imposible. Hegel afirma la unicidad de la filosofía y, al mismo tiempo, remite a la pluralidad de su proceso intelectual, espiritual. La idea hegeliana es ésta: todas las filosofías. son la filosofía en menor o mayor grado -cuestión, nuevamente, de criterio.

\section{III}

A puremos algo más las cosas. Hegel, en efecto, trata de precisar con rigor qué debe hacerse en una filosofía de la historia de la filosofía.

Son tres las cosas que habrá que hacer.

En primer lugar habrá que "determinar qué es la historia de la filosofía, su significación, su concepto de un fin". Ya sabemos que tal determinación implica, ciertamente a priori, que la historia de la filosofía es la filosofía misma.

En segundo lugar, hay que precisar "el concepto de la filosofía" y deslindar, en la historia de los pueblos, lo que es verdaderamente pensamiento filosófico y lo que no lo es. El punto de partida de las Lecciones consistirá en distinguir la filosofía de otros campos del saber.

En tercer lugar, será necesario tener siempre en mente una "visión de conjunto" y, al mismo tiempo, como en el caso de las distintas "fases" de la Filosofía de la historia, habrá que precisar las "divisiones" históricas en "sus periodos necesarios", para alcanzar una "cohesión racional".

Veamos estos tres puntos cruciales si queremos entender el sentido que Hegel quiere dar a la filosofía de la historia de la filosofía, la "esencia" de la "verdad" de todas las filosofías ... "verdaderas". 
La filosofía es, para Hegel, un saber "eterno" e "inmutable". El problema consiste en ver cómo se puede reconciliar este carácter de inmutabilidad con el movimiento histórico de la filosofía.

También la religión es un "saber eterno" pero, lo veremos más adelante, la religión se aparta de la filosofía en cuanto la guía, ante todo, la fe; a la segunda la guía la razón, el espíritu. Ciertamente, Hegel cambió en su concepto de la religión de sus años juveniles a sus años maduros. En los escritos juveniles de Hegel, amigo de Hölderlin y de Schelling, pensaba, como lo pensará después, que la. religión evoluciona, a pesar de muchas “aberraciones" históricas. ${ }^{11}$ En julio de 1874, Hegel recibe una carta de Hölderlin que se inicia asi: "Estoy seguro te has acordado a veces de mí, desde que nos separamos con la consigna 'Reino de Dios'". Al escribir esta carta, Hölderlin y Hegel frisaban en los veinticuatro años. Ambos, acaso también Schelling, querían reformar, renovar totalmente la religión cristiana. A los treinta años, Hegel escribía este texto revelador:

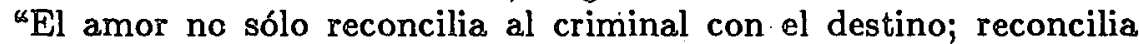
también al hombre con la virtud. Es decir, si el amor no fuera el único principio de la virtud, cada virtud sería, al mismo tiempo, falta de virtud". Esta actitud de Hegel no es la de su madurez que se quiere más racional. Es probable que Schelling, Hegel, Hölderlin hubieran consultado y acaso tratado de formar corrientes herméticas más o menos secretas.

La religión, en efecto, evoluciona y prógresa hacia mayor espiritualidad. También las ciencias progresan. En cuanto a la filosofía parece progresar si sólo nos quedamos con las apariencias. Hegel puede escribir que "en apariencia", la filosofía parece haber sufrido "cambios incesantes". Pero, esta visión "externa" de la filosofía es, para Hegel, absolutamente falaz; lo es porque no debe concebirse, como lo hacía el hombre culto común y corriente, que la filosofía consiste en un mero "acervo de opiniones". La filosofía, sin embargo, no se queda en el reino de la doxa, aunque, platónicamente, sea la doxa verdadera; la filosofía busca un saber científico; lo que afirma no es opinión sino episteme. Escribe Hegel en su Introduccióñ

11 Sobre Hegel juvenil es indispensable la obra magistral de José Marfa Ripalda. Véase G. W. F. Hegel, Eocritoo juverileo, México, Fondo de Cultura Económica, 1978. Indispensables para este periodo: H. S. Harris, Hegel'o Developmert. Toward the Sunlight (1770-1801), Oxford, 1972; Georg Lukács, El joven Hegel y loo problemao de la oociedad capitalista, México, Grijalbo, 1970. Sobre el tema de la religión, véase el texto hegeliano El concepto de religión, traducción y estudio preliminar de Arsenio Guinzo, México-Madrid-Buenos Aires, Fondo de Cultura Económica, 1981. 
a las Lecciones: "la filosofía no contiene nunca opiniones. La religiosidad puede ser subjetiva e individual; la verdad no es subjetiva ni es convencional o caprichosa". Románticamente -y jcómo es romántico Hegel en su anti-romanticismo!-: "para el hombre imparcial, la verdad será siempre una gran palabra que hará latir siempre el corazón".

También únicamente en apariencia, la historia de la filosofía consta únicamente de una sucesión continua de sistemas que se contradicen entre sí. Pero la "verdadera" filosofía - ¿dónde está aquí el criterio de verdad? - se ve siempre guiada, aunque no lo sepa, por el "instinto de la razón", expresión ésta sorprendente en quien no parece identificar razón e instinto.

Al tratar de explicar la unicidad de la filosofía, algunas veces Hegel parece anunciar a Unamuno; la vida, como el espíritu, nunca están satisfechos. Los hombres tienen "hambre y sed de verdad" y esta verdad es la que tienen en común todas las filosofías... verdaderas; es lo que hace que las filosofías sean filosofías.

Sin embargo, la diversidad y aun oposición de los sistemas filosóficos parece subsistir. Por lo demás Hegel cree que la variedad es "algo necesario para que exista la ciencia filosófica". Pero partamos del centro y corazón mismos del pensamiento de Hegel: la fe en "el espíritu del mundo". De esta fe, y no de una razón muy precisa, parte Hegel para ver y entender la filosofía de la historia de la filosofía.

\section{$\mathrm{V}$}

Hasta aquí me he limitado a decir que la verdad es única, lo cual no deja de ser muy abstracto y muy formal. Para encontrar los criterios que con Hegel andamos buscando, hay que dirigirse a lo que el filósofo llama "la fuente de todo filosofar". Los "criterios" que Hegel elige para dirigirse a esta "fuente" son casi, punto por punto, los de su propio sistema; lo que metafóricamente llama "fuente" filosóficamente significa Idea. Pasemos a los criterios.

El primero proviene del "concepto de evolución", una evolución. que camina entre el en-sí (potencia, dynamis) y el ser para-sí (acto - energeia). La razón no se da en acto en el caso del niño. Así, evolución significa tanto un primer estadio que podemos llamar embrionario al estadio realizado, es decir, al "fruto". De esta manera, en muy buena medida, la filosofía "deviene". Pero, en forma dialéctica, hay que decir que "lo simple y a la vez diferente" es necesario para que la filosofía evolucione. La verdad es así, y en una primera aproximación, "proceso", "movimiento", "verdad total y concreta". 
Ahora bien, y siguiendo una idea que Hegel repite, la evolución en general y ahora la evolución de la filosofía no es lineal. Es circular. Así, hay que concebirla como "una circunferencia que tiende, como tal, a volver sobre sí misma y que tiene como periferia una multitud de circunferencias que forman, en conjunto, una gran sucesión de evoluciones que vuelven a sí mismas"; de la misma manera, podríamos añadir que la Idea, aún vacía en la noción abstracta de Ser, vuelve, culminación del Espíritu Absoluto, sobre sí misma, ya llena de todas las realidades que constituyen el "todo" que Hegel no deja de buscar. ${ }^{12}$

La filosofía debe ser vista como el conocimiento del "concepto en su evolución puesto que solamente ló vivo, lo espiritual, se agita dentro de sín. ${ }^{13}$ La filosofía evoluciona y esta evolución constante y "pensante" culmina en este Dios, pensamiento del pensamiento, que es la Idea. Pero el progreso, en filosofía como en cualquier otra ciencia o realidad, solamente es posible gracias a los obstáculos o, más hegelianamente, gracias al "antagonismo".

Toda filosofía "verdadera" es un sistema; la filosofía que subyace a la historia toda de la filosofía, se asemeja mucho a la propia filosofía de Hegel.

Si aceptamos, para explicar mejor las cosas, lo que Hegel viene diciendo, podrá entenderse que las diferentes "fases" por las cuales pasa la historia de la filosofía se completan sucesivamente en el tiempo, aun cuando su verdad sea extratemporal. Por decirlo con Hegel, la evolución del pensamiento filosófico es la "derivación de las formas". En otras palabras, las variedades filosóficas, en el fondo unidades ya' que toda filosofía es ciencia, son las mismas que Hegel hace explícitas en su Lógica que, ya lo hemos dicho, es también su ontología. Como toda filosofía verdadera, la del pasado se hace presente en Hegel. Así escribe: "... de lo dicho se desprende que el estudio de la historia de la filosofía es el estudio de la filosofía misma y no podría ser de otro modo", lo cual significa que para escribir una historia de la filosofía, en su carácter a la vez sucesivo y absoluto, inmóvil, eterno, es necesario tener ya un conocimiento de la Idea, esta divinidad que Hegel llama la "Personalidad pura".

12 Esta “totalidad” será, en términos de Franz Grégoire, “identidad de lo real y lo posible y no dejará nada fuera de si". Véase op. cit. Por lo demás, Hegel habla escrito, al definir el Absoluto (Lógica, II, p. 214), como sustancia” que está constituida por "la identidad de lo real y lo posible". Comenta Grégoire: “... el todo es para él el Absoluto".

13 "Concepto" no traduce bien el alemán Begriff, medular en toda la obra de Hegel. Para precisar el término remito nuevamente al libro de Franz Grégoire, mencionado en la nota anterior. Alli se ve que el Begriff (el concepto) se acerca a la espiritualidad hasta llegar a ser la misma Idea Absoluta. 
Resumamos: "Solamente merece el nombre de ciencia una historia de la filosofía concebida como un sistema de la evolución de la Idea" y aceptar esta ciencia es ya tener lo que Hegel llama una "fe racional".

A fin de cuentas, la historia de la filosofía vista filosóficamente es "variedad", pero es "variedad dialéctica" y tiene que ser captada esencialmente en el movimiento de la evolución como un momento pasajero. Las verdaderas filosofías del pasado, distintas entre sí, deben sèr cada una de ellas un "todo" y tener en sí lo invariable, la "realidad de la Idea".

Hegel piensa que la variedad de criterios no significa arbitrariedad sino necesidad porque "las formas parciales se integran en la forma total". En suma, si entiendo a Hegel, cada "momento" o "fase" del desarrollo racional que la filosofía constituye es un todo completo que, sin ser negado, se racionaliza más y más al pasar del tiempo y alcanzar, poco a poco, el Espíritu; es decir, el pensamiento racional, guiado por nuestro ya conocido y misterioso Espíritu del Mundo, aumenta más y más en libertad hasta alcanzar, sucesivamente, en Arte, Religión, Filosofía, la plena libertad y el verdadero "estar en casa" que es "reconciliarse" con la "realidad". El proceso de espiritualización de la filosofía y de la historia de la filosofía que es ahora su objeto, es lento, pero, como dice Hegel, "el Espíritu del Mundo no necesita apresurarse... tiene tiempo de sobra precisamenite porque vive al margen del tiempo, porque es eterno". Y si la Naturaleza tiende a cumplir sus fines por el camino más corto, el Espíritu se realiza, de una limitación a otra en su aspiración infinita, por "el camino de la mediación y el rodeo".

\section{VI}

Todo lo escrito hasta aquí lleva a ciertas consecuencias tal vez claras.

1. La historia de la filosofía concebida en su totalidad e ignorando al pensamiento chino e hindú, que Hegel no considera filosóficos, "es el proceso necesario y consecuente, racional de suyo y determinado a priori por su Idea". De modo que aquí, como en la historia humana a secas, los principios racionales que brotan de la Idea son universales y necesarios, son a priori. Si hacemos a un lado todo lo relativo y contingente y tratamos de acercarnos a lo "infinito" veremos que "lo finito no es nunca verdadero ni debe serlo". Mucho de lo que desaparece en el curso de la historia de la filosofía es aquello que no es filosofía.

2. De lo anterior se deduce que toda filosofía verdadera fue y sigue siendo "necesaria". Las filosofías consideradas así forman parte 
de la filosofía y, especialmente, de la "novísima filosofía" alemana. Pero, ¿qué es en filosofía lo que no es filosofía? Curiosamente Hegel condena como anti-filosófico o a-filosófico el atomismo, griego o no griego. El atomismo ha sido "refutado", pero lo refutado no es inútil puesto que el refutar nos permite ir hacia adelante por los senderos de la Idea, por el Espíritu del Mundo, por la libre racionalidad humana.

3. Es frecuente tener que abandonar aspectos no verdaderos de filosofías pasadas. Un ejemplo: la filosofía platónica de la naturaleza que Hegel califica de "muy pobre"; así, la aplicación a la naturaleza de las ideas de Descartes - lo cual es, por lo menos, dudoso. Solamente serán verdaderas las filosofías que tengan claros principios, aun cuando Hegel no precise esta noción de "principio".

\section{VII}

Escribe Hegel que "toda filosofía es filosofía de su tiempo, y un eslabón en la gran cadena de la evolución espiritual". Por lo cual Platón y Aristóteles no pueden ser "resucitados", afirmación por lo menos poco clara. Hay mucho de Platón en la filosofía medieval, moderna y contemporánea; hay mucho de Platón en la filosofía de Hegel. Por otra parte Hegel dice que "hay que buscarse", sin aceptarlo del todo, en el pensamiento de los antiguos aunque en los tiempos "novísimos" "laten ideas más profundas" que las expresadas por los griegos. Ejemplo: las de la libertad, la Providencia y el origen del mal. Exactos o no los juicios de Hegel, es cierto que además de incorporar en su sistema a muchos pensadores del pasado, también polemiza con los filósofos que expone; así con Descartes, a quien sin duda respeta pero cuyo dualismo le parece discutible, como en efecto lo es; así con Spinoza, a quien admira profundamente (¿ambos panteístas?) que a veces se reduce a ver "las cosas como aparecen" y no, como lo desea la especulación hegeliana, como "cosas en sí". Pero volvamos a tratar de precisar algo más el pensamiento de Hegel en cuanto a filosofía de la historia de la filosofía.

\section{VIII}

Hay que repetirlo: las "formas" en que la filosofía se manifiesta son verdaderas "y en ellas un espíritu y solamente uno... se manifiesta y se plasma a través de... diversos momentos". Pero la filosofía está, en palabras de Hegel, "aprisionada", "condicionada" por las circunstancias de su "momento". Hay que tratar de ver la historia de la filosofía regida por principios a priori, universales y necesarios. 
En efecto, la filosofía es "pensamiento de su tiempo" aunque, si es verdadera, pueda ir más allá del tiempo, como más allá de su tiempo van la historia de los Estados, el arte, la ciencia, la religión, a la vez condicionadas y libres cuando son ciertas.

Para precisar más el sentido de la filosofía y de la razón es necesario ver cómo se relacionan y se separan entre sí la religión y, justamente, la filosofía misma.

En la Nota preliminar a $E l$ concepto de la religión, Hegel escribía: "El objeto de estas lecciones es la Filosofia de la religión, y el objeto de la religión misma es el más elevadí, el absoluto" ${ }^{14}$ La religión es, en Hegel, el grado más alto del saber absoluto solamente sobrepasado por el Dios-Idea, es decir, el Dios espiritual-racional. Así, cuando Hegel en sus Lecciones sobre la historia de la filosofía remite al tema de la filosofía y de la religión, en buena medida - ambas se refieren al Absoluto- están ligadas entre sí.

Históricamente hablando, la religión es anterior a la filosofía; ésta, al desarrollarse, podrá abarcar a la religión. 'Pero al discurrir acerca de la historia de la filosofía no debe recurrirse a la religión, siempre revelada y siempre objeto de fe. En otras palabras, la religión, aquí, como en Kant, tendrá que ser analizada por la filosofía, grado supremo de la espiritualidad. Esto es posible porque la religión, este "santuario de la verdad misma" como la llama Hegel, tiene en sí algún contenido racional aunque esta racionalidad no se muestre, como lo hace en la filosofía, por las vías de la argumentación lógica sino por la "devoción" y "el pensamiento proyectado más allá". La teología puede ofrecer "filosofemas" pero no constituye una filosofía y, menos aún, la filosofía. Además, ya lo indiqué brevemente, filosofía y religión difieren por el modo y manera de conocer. Hegel piensa que la teología es mala filosofía y que la religión verdadera, sin carecer de elementos "pensantes" debe ser vivida en Cristo, quien no conoció a Dios por medio de la Naturaleza sino por medio del Espíritu. La religión es, así, más "intuitiva" que la filosofía; en ella no se han realizado todavía todos los "contenidos" que solamente estarán plenamente realizados en esta "Persona" que es la Idea. El cristianismo es, para Hegel, la más verdadera de las religiones - ¿hasta qué punto sigue Hegel pensando, ya maduro, en aquel "reino de Dios" que le recordaba, en plena juventud, Hölderlin? En religión, la verdad se da a los hombres por la gracia y la fe. Hegel, que todavía afirma que sigue siendo luterano - lo cual es proba-

14 Véase G. W. F. Hegel, El concepto de la religión, Mexico, Fondo de Cultura Económica, 1981. Arselio Guinzo es el autor del prólogo y el traductor, excelente, de este libro publicado por primera vez en alemán en 1925. 
ble aunque no lo acepten algunos de sus comentaristas, entre ellos Kaufman- ${ }^{15}$, cree que con la Reforma se alcanzó la "fe originaria".

IX

¿Qué es necesario para que una filosofía sea "verdadera filosofía"? ¿Cuál es la condición, no tanto el origen de ésta? La condición necesaria es que exista la libertad y, más aún, lo que Hegel llama "libertad de pensamiento". Ni Oriente ni' el mundo judío concibieron la libertad auténtica. Ésta nació con Grecia, donde empezó a mostrarse de veras el Espíritu del Mundo, ahora pensado. La libertad a la cual remiten las Lecciones nada tiene de abstracto; es la libertad de expresión y es la libertad política, ambas, por cierto, ya buscadas con intensidad por Kant. Dos momentos en que se muestra el espíritu racional: Grecia y, después, los pueblos "germánicos", donde Hegel incluye a Francia, Inglaterra, Italia, España, Alemania. Grecia, según Hegel, pensó la Idea; el mundo germánico, y especialmente el mundo alemán, han pensado según la Idea y según el Espíritu.

En la historia misma de la filosofía, que ahora no puedo ni deseo seguir con detalle, Hegel, ya lo vimos, a veces polemiza; otras veces "hegelianiza" (¿hay otro modo de decirlo?) a los pensadores que considera más afines. En Grecia, primum inter pares, Heráclito de Efeso, creador, al modo de ver de Hegel, de la dialéctica; de igual modo Anaxágoras, primigenio y también algo primitivo, creador de la noción del Espíritu, del nous. Por lo que toca a la Edad Media, Hegel da pruebas de una verdadera ignorancia, típica, es verdad, de su tiempo. Santo Tomás, por ejemplo, merece menos de una página. En cambio le merece largos desarrollos el místico zapatero, Jacob Böhme, en cuya obra ve, preformada y aún rústica, su propia filosofía y, en general, la filosofía "germánica". Por "grosero" que sea, Böhme es ya pensador no únicamente germánico, sino, más precisamente, alemán.

Resumamos con una larga cita del propio Hegel:

Nos hemos esforzado en seguir esta trayectoria de las formaciones espirituales de la filosofía en su desarrollo, aludiendo a sus conexiones, y en hacerla desfilar ante ustedes. Esta serie es el verdadero reino de los espíritus, el único reino de los espíritus que existe; una serie que no es

15 Algunos, entre los que se encuentra Waiter Kaufman en Hegel: Reinterpretation, 1968, piensan que Hegel dejó de ser luterano. Es difícil saber ló que pensaba de verdad Hegel en cuanto a la religión; parece que debemos inclinarnos a aceptar lo que él dice de sí mismo. 
simplemente una pluralidad, [una serie que] se convierte en momentos del Espíritu (Geist) uno... Este largo cortejo de espíritus son las distintas pulsaciones que van jalonando el camino de la vida; son el organismo de nuestra sustancia, un proceso simplemente necesario que no proclama otra cosa que la naturaleza del Espíritu mismo y que vive en todos nosotros. A sus latidos debemos prestar oídos y procurar infundirles realidad. Deseo que esta historia de la filosofía les incite a comprender el espíritu de nuestro tiempo, que nos es natural y a sacarlo de su naturalidad, es decir, de su encierro sin vida, a la luz del día - cada uno desde su sitiode manera totalmente consciente.

30 DE ENERO DE 1988

\section{BREVE NOTA BIBLIOGRÁFICA}

De Hegel he consultado principalmente las Lecciones sobre la historia de la filosofía. (A lo largo del texto he abreviado y escribo solamente Lecciones.) Sobre Hegel, aparte de los textos citados a pie de página, recomiendo especialmente:

J. N. Findlay, The Philosophy of Hegel. A Re-examination, 1958.

Antonio Negri, La presenza de Hegel, 1961.

W. Adorno, Drei Studien zu Hegel, 1963.

Claude Bruaire, Logique et Religion Chrétienne dans la Philosophie de Hegel, 1964 (dos volúmenes).

Ivan Soll, An Introduction to Hegel's Metaphysics, 1969.

Darrel Christensen (comp.), Hegel and the Philosophy of Religion, 1970.

H.-G. Gadamer, Hegels Dialektic, 1971.

H. S. Harris, Hegel's Development, 1972.

Antonio Escohotado, La conciencia infeliz, 1972.

Charles Taylor, Hegel, 1975. 